\title{
Regression models for compressive strength of concrete under different curing conditions
}

\author{
Kolawole Adisa Olonade ${ }^{1}$, Heni Fitriani $^{2}$ and Olutobi Toluwalase Kola ${ }^{1}$ \\ ${ }^{1}$ Department of Civil Engineering. Obafemi Awolowo University, 220005 Ile-Ife, Nigeria \\ ${ }^{2}$ Faculty of Engineering, University of Sriwijaya, 30662 Palembang, Indonesia
}

\begin{abstract}
Effect of different curing methods on the compressive strength of concrete was investigated. A total of 69 concrete cubes of size $150 \mathrm{~mm}$ was cast and cured under five different conditions (immersion in water, sprinkling with water, moist sand covering, polythene covering and air curing) for 3, 7, 14 and 28 days. At the expiration of curing ages, compressive strength was determined and regression analysis was conducted. The concrete cured with these techniques was equally subjected to water penetration test. The results showed that Polythene covering method produced concrete specimen with the highest compressive strength of $23.41 \mathrm{Nmm}^{-2}$ followed by Immersion in water $\left(22.86 \mathrm{Nmm}^{-2}\right)$. Regression models formulated for each condition indicated that the strength development was dependent on methods of curing. From the results, it was concluded that the compressive strength of concrete depends on the medium in which they were cured and there exist a positive correlation between the compressive strength of concrete and curing age.
\end{abstract}

\section{Introduction}

Moisture is essential to the performance of cement-based products. When water is added to a mixture containing cement, hydration reaction begins. The extent to which this reaction continues has great influence on both mechanical and durability of concrete. Though, freshly mixed concrete contains more water than required for hydration reaction but due to the fear of loss of water through evaporation, which could inhibit further hydration reaction. Thus, there is need to keep the conrete matrix saturated or near saturated as much as possible to facilitate anhydrous portion of cement to take up water through curing.

Curing usually has immediate effect on the surface zone, the depth of which varies depending on the type of curing techniques adopted and ambient environmental conditions. It is estimated that the depth at which the curing directly affect concrete is about $20 \mathrm{~mm}$ in temprate climate region and up to $50 \mathrm{~mm}$ in extreme arid conditions [1]. Unfortunately, those regions beyond these depths are not significantly affected by normal curing technique (wetting). For this reason, effectiveness of curing technique on the strength properties could partly be linked with the size of concrete element. Slender elements would be more affected than bulk ones.

According to [2], cement needs about $23 \%$ of water of its weight for hydration to proceed and $15 \%$ for filling the space or voids of gel, while [3] reported that 0.22 grams of water is required to fully achieve hydrated cement of about $1 \mathrm{~g}$. If the required amount of moisture is not available for complete hydration, there would be region of anhydrous substance that could be a window for attack. It is equally identified that improper curing entails insufficient moisture and this has been found to produce cracks, compromise strength, and reduce longterm durability [4]. On the other hand, proper curing of concrete is essential to obtain maximum durability of concrete [5].

A number of curing techniques have been identified such as water ponding, spraying of water, or covering with wet burlap and plastic sheet [5]. However, there is still dearth of information as to which curing condition could be considered as the best. Meanwhile, effectiveness of any curing technique is a function of extent of time it can maintain moist condition and also temperature [7]. The rise in temperature speeds up the hydration reaction while water facilitates the reaction.

Reference [8] studied the effect of immersing concrete in water for curing on compressive strength of concrete. They found that the strength of specimens cured by immersion in water was about 30 percent higher than that cured in air. Many other researchers reported similar findings [9-10]. The work reported by [11] suggested that moist sand curing method produced specimens with the highest compressive strength when compared with sprinkling methods. However, [10] opines that sand curing method could cause patchy discoloration especially, if the sand contains calcium chloride, which could negatively affect performance. Reference [12] reported that wrapping curing is more efficient than air curing as it results in greater

Corresponding author: olonade1431ah@gmail.com 
compressive strength. Membrane-forming curing compounds, self curing agents as well as accelerated curing are some other techniques that are found effective [13-15].

A careful perusal of the literature pointed that quite a number of curing techniques have been studied with comparison of three or four methods. Subsequently, there appears to be dearth of information on comparison for wider range of techniques. The thrust of this present work, therefore, is to compare more techniques with a view to rating the performance of each technique on the compressive strength of concrete. In addition, the paper also formulates a regression model that could be used to predict the compressive strength of concrete for different curing techniques.

\section{Materials and method}

\subsection{Materials}

Ordinary Portland cement of grade 32.5 was used as binder. Fine and Coarse aggregate used was river sand and crushed granite of maximum nominal size of 3.48 $\mathrm{mm}$ and $12.5 \mathrm{~mm}$ respectively. Potable water was used for mixing the concrete. Concrete of mix ratio $1: 2: 4$ was batched by weight. A water cement ratio of 0.56 was used to keep the slump in the range of $65 \pm 15$ to maintain relatively constant consistency [16]. Thereafter, 69 concrete cubes of size $150 \mathrm{~mm}$ were cast.

\subsection{Curing of specimen}

Six curing techniques were considered in this study. The choice of the selected techniques was deliberate. Apart from accelerated curing, others techniques are commonly found in construction sites especially in most developing countries like Nigeria.

- Immersion in water: The concrete cube specimens were submerged in water for the required number of days until testing (Figure 1a).

- Sprinkling with water: Water was sprinkled on the concrete cube specimens daily (Figure 1b).

- Polythene covering: The specimens were wrapped/covered with polythene membrane (nylon) for the required age of curing (Figure 1c).

- Air Curing: No active form of curing was carried out. The specimens were left exposed in the Laboratory (Figure 1d).

- Moist Sand: The entire concrete cube specimens were buried in sand which was kept moist by wetting with water on a daily basis. Sand cover of approximately $150 \mathrm{~mm}$ was provided (Figure 1e).

\subsection{Determination of material properties}

The chemical composition of the cement used in this study was determined using XRF technique, while the gradation parameters of the aggregates were determined in accordance with [17].

\subsection{Determination of compressive strength}

Compressive strengths of the concrete cubes cured using the techniques identified were determined at the expiration of 3, 7, 14 and 28 days; and after 6, 9 and 12 hours for accelerated curing. The procedure highlighted in [16] was adopted in determining the compressive strengths. Average of three values was determined for each specimen. The 28-day strength of the accelerated curing was obtained using the model proposed by Regressions Models for Predicting Compressive Strength under different curing techniques. Regression analysis was conducted on the compressive strength values obtained. Using MS Excel software, equation that represents the line of best fit was established. Pearson's correlation coefficient was determined for each model.

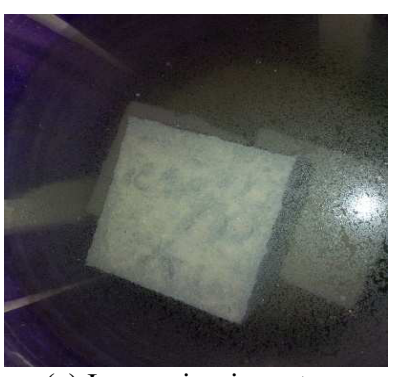

(a) Immersion in water

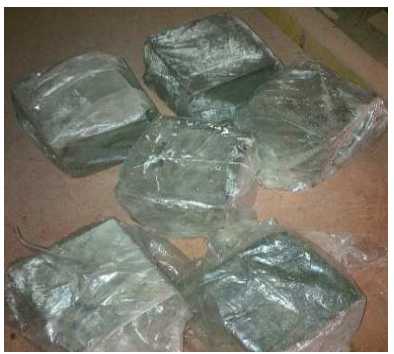

(c) Polythene covering

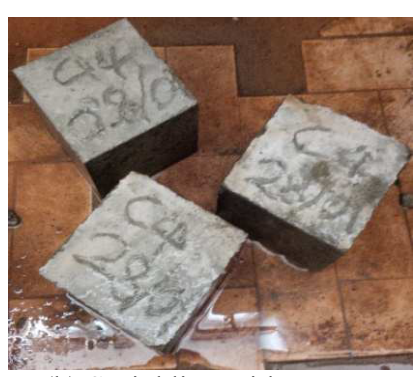

(b) Sprinkling with water

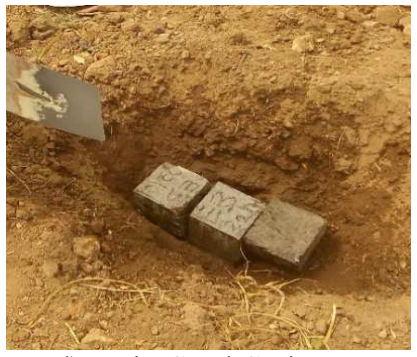

d) Moist Sand Curing

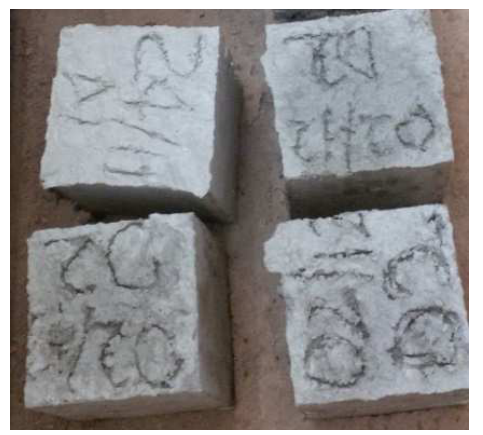

(e) Air Curing

Fig. 1. Curing of concrete under different conditions

\subsection{Determination of efficiency of curing techniques}

In order to determine effectiveness of each of the curing techniques, curing efficiency was determined for each using equation (1) as proposed by [17] 


$$
E=\frac{k_{1}-k_{2}}{k_{1}-k_{3}} \times 100
$$

where:

$\mathrm{E}=$ Efficiency $(\%)$

$\mathrm{k}_{1}=$ the compressive strength of concrete cured in air $\left(\mathrm{N} / \mathrm{mm}^{2}\right)$

$\mathrm{k}_{2}=$ compressive strength of concrete cured in the medium being evaluated $\left(\mathrm{N} / \mathrm{mm}^{2}\right)$

$\mathrm{k}_{3}=$ compressive strength of concrete cured in water $\left(\mathrm{N} / \mathrm{mm}^{2}\right)$

\subsection{Water absorption capacity of concrete cured under different techniques}

Effect of the curing techniques considered in this study was evaluated by determining water absorption and depth of water penetration in concrete cured by the techniques. Concrete cubes were cured using different techniques for 28 days. Thereafter, they were dried in oven for 24 hours at temperature of $60^{\circ} \mathrm{C}$.

The temperature chosen was to minimize damage to microstructure of the hardened concrete. For penetration test, about $5 \mathrm{~mm}$ of the surface of the concrete cube was held in contact with water (Figure 2) and rise in water by capillary was monitored. This was noticeable by change in colour of the layer of the concrete soaked with water. The depth of water rise in the concrete was recorded at every 30 minutes until no physical rise in water was noticed. In water absorption test, the dried concrete cubes were weighed before they were soaked in water for 24 hours, after which their weights were measured. Water absorption capacity was determined using Equation (2).



Fig. 2: Penetration depth set-up

$$
W A C=\frac{W_{d}-W_{w}}{W_{d}} \times 100 \%
$$

where:

$\mathrm{WAC}=$ water absorption capacity $(\%)$

$\mathrm{W}_{\mathrm{d}}=$ weight of dried concrete $(\mathrm{kg})$

$\mathrm{W}_{\mathrm{w}}=$ weight of concrete after soaked in water for 24 hours $(\mathrm{kg})$

\section{Results and discussion}

\subsection{Material characterization}

The chemical composition of the ordinary Portland cement (OPC) used, as determined from XRF technique, is presented in Table 1. Also shown in the table are the mineral contents obtained, using Bogue's equations. The values indicated that the oxides contents were within the stipulated limits given by [18]. Thus, the cement could be categorized as CEM I (general purpose cement). Fig. 3 shows the particle size distribution of the aggregates used in the study. The pattern is in accordance of materials accepted for concrete works [19].

Table 1. Chemical and mineral composition of the cement in comparison with bs en 196

\begin{tabular}{|c|c|c|}
\hline Oxides & Cement & BS EN 196-2 [18] \\
\hline $\mathrm{SiO}_{2}$ & 20.48 & $18-24$ \\
\hline $\mathrm{Al}_{2} \mathrm{O}_{3}$ & 5.02 & $2.6-8.0$ \\
\hline $\mathrm{Fe}_{2} \mathrm{O}_{3}$ & 3.15 & $1.5-7.0$ \\
\hline $\mathrm{CaO}$ & 62.45 & $61.0-69$ \\
\hline $\mathrm{MgO}$ & 1.92 & $0.5-4.0$ \\
\hline $\mathrm{Na}_{2} \mathrm{O}$ & 0.61 & - \\
\hline $\mathrm{K}_{2} \mathrm{O}$ & 0.72 & $0.2-1.0$ \\
\hline $\mathrm{SO}_{3}$ & 0.18 & $0.2-4.0$ \\
\hline $\mathrm{LOI}$ & 4.76 & - \\
\hline Minerals & & \\
\hline $\mathrm{C}_{2} \mathrm{~S}$ & 59.74 & \\
\hline $\mathrm{C}_{3} \mathrm{~S}$ & 13.36 & \\
\hline $\mathrm{C}_{3} \mathrm{~A}$ & 7.98 & \\
\hline $\mathrm{C}_{4} \mathrm{AF}$ & 9.59 & \\
\hline
\end{tabular}

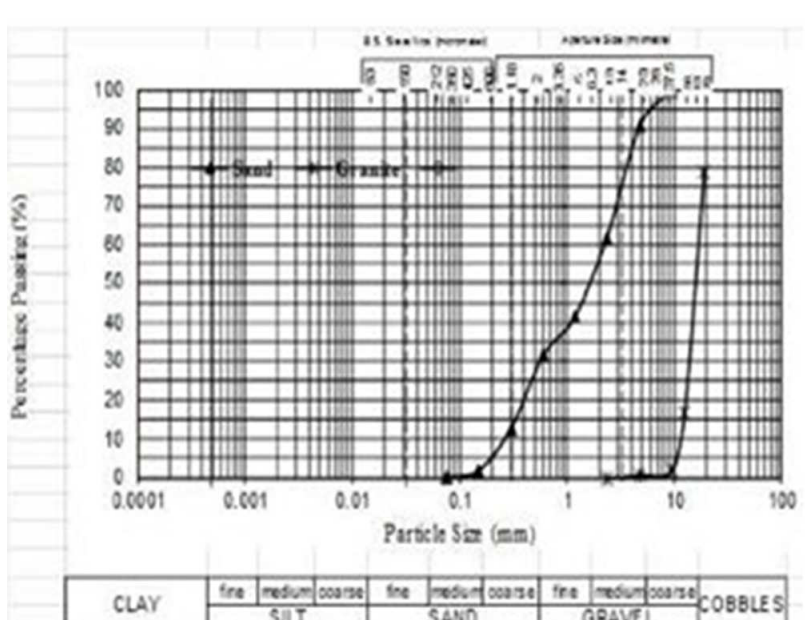

Fig. 3. Particle distribution curves of the aggregates

\subsection{Effect of curing methods on compressive strength}

In all the curing methods, the compressive strength of the concrete increased with increasing ages of curing (Figure 4). The increase in strength might be associated with production of various silicate hydrates as hydration reaction progressed. It is a known fact that silicate hydrates contribute to increase in strength by filling the voids in concrete matrix. As long as these voids are sufficiently filled with hydration products, the quality of concrete will be maintained at a satisfactory level [19]. 
Compressive strength obtained varied as the curing methods varied, indicating that curing condition influences compressive strength (Figure 1). For example, at age 28 days, the compressive strength of concrete cured by polythene covering was highest $\left(23.41 \mathrm{Nmm}^{-2}\right)$, while air curing gave lowest strength of $13.94 \mathrm{Nmm}^{-2}$ (60\% of polythene covering). Strengths obtained from immersion in water and burying in sand were about $2 \%$ and $10 \%$ respectively lower than that of the polythene covering, while that of sprinkling with water was about $20 \%$ lower. These results are comparable to those reported by [14].

The relative low strength obtained from air curing could be partly attributed to loss of moisture from the concrete through evaporation, subsequently slowing down or retarding hydration of cement; hence low strength [20]. Though, air curing may likely produce higher strength if the relative humidity is maintained at a value greater than $80 \%$ [21] as against $70 \%$ in this case. Another possibility of low strength in air curing is carbonation, which would interfere with hydration process. Conversely, better perform was given by Polythene covering, where moisture in the concrete matrix was not allowed to escape into the atmosphere and was fully utilized during hydration process.

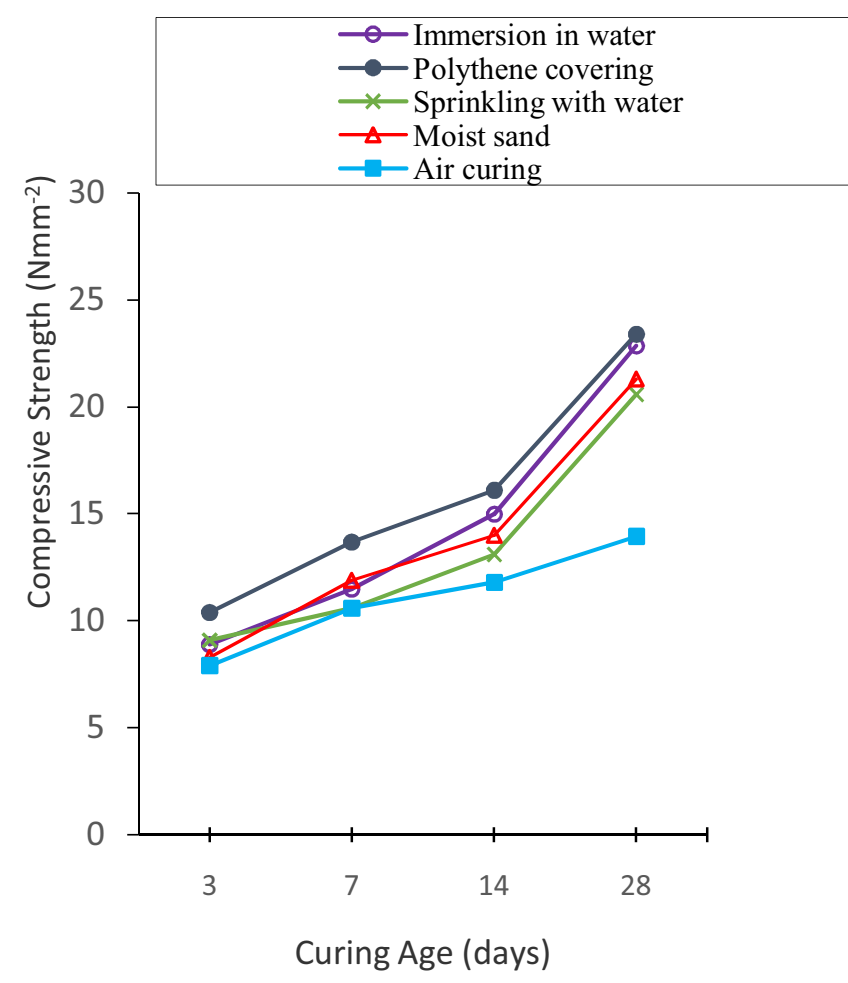

Fig. 4. Compressive strength of concrete under different curing conditions

For total immersion, the strength obtained was in contrary to what [9] obtained in their study, where it was reported that immersion in water gave the best strength. The reason may not be readily known but experimental handling, type of water used, difference in ambient environmental conditions and material constituents could be responsible. Similarly, results from this study indicated that strength of concrete cured by immersion in water was about $60 \%$ higher than that of air curing as against $30 \%$ obtained by [8]. Though concrete cured by layer of moist sand gave relative higher strength (Figure 3 ), the method lead to patchy coloration of concrete element, and could have exposed to acidic attack especially, if the soil contains deleterious substances.

\subsection{Regression models for compressive strength under different curing methods}

Relationship between compressive strength $\left(f_{c}\right)$ and curing ages in days (t) was established using regression analysis, and (1) to (5) were obtained for the different curing techniques considered. These equations further affirmed that there was strong correlation between the compressive strength and curing ages as the Spearman's correlation coefficients were close to 1 for all the equations $(0.87$ - 0.98). These coefficients, as they approached unity, suggested that the models could be used to predict compressive strength for each of the curing techniques at any given age, all other factors being equal. Nevertheless, the rate of strength development as indicated by the gradients of the equations varied from one technique to the other. The Polythene covering, for instance, had rate of 4.54 (2) followed by immersion in water (1), while air curing had the least (4). The relative low rate of strength development seen in (3) for sprinkling with water could be partly attributed to partial exposure of the concrete to the atmosphere, leading to evaporation of moisture; hence slow hydration process.

$$
\begin{array}{ll}
f_{c}=4.14 t+3.22 & (\mathrm{R}=0.93) \\
f_{c}=4.54 t+5.55 & (\mathrm{R}=0.94) \\
f_{c}=3.68 t+4.11 & (\mathrm{R}=0.87) \\
f_{c}=1.93 t+6.23 & (\mathrm{R}=0.98) \\
f_{c}=4.11 t+3.60 & (\mathrm{R}=0.95)
\end{array}
$$

\subsection{Efficiency of curing techniques method}

Efficiency of a curing technique is a measure of its effectiveness in influencing concrete properties. The results of efficiency computated suggested that sprinkling of water technique was not as efficient in improving compressive strength of the concrete when compared with immersion in water because its efficiency was less that $100 \%$ (74.4\%). Moist sand was equally less efficient than water with efficiency of $80.1 \%$. It is interesting to note that polythene covering had about $106.1 \%$ efficiency, indicating that it was more effective than water curing. The reason for this performance has could be attributed to preserving mixing water from evaporation. As for curing in air, the efficiency is $0 \%$ while that of immersion in water was $100 \%$. If the provision of [23], which stipulated minimum efficiency of $85 \%$, then only polythene covering and immersion in water methods of curing med the requirement, while 
buried in moist sand was close to the requirement $(80.1 \%)$.

\subsection{Effect of curing techniques on water absorption and penetration}

Water penetration depth was found to be the highest in concrete cured in air, while polythene covering had the lowest penetration depth (Fig. 5). The results seem to suggest that the concrete sample cured in air was more porous than other, which made water to travel through it. This assertion is supported by the water absorption capacity of the concrete sample cured in air (Fig. 6).



Fig. 5. Water penetration depth for concrete cured using different techniques

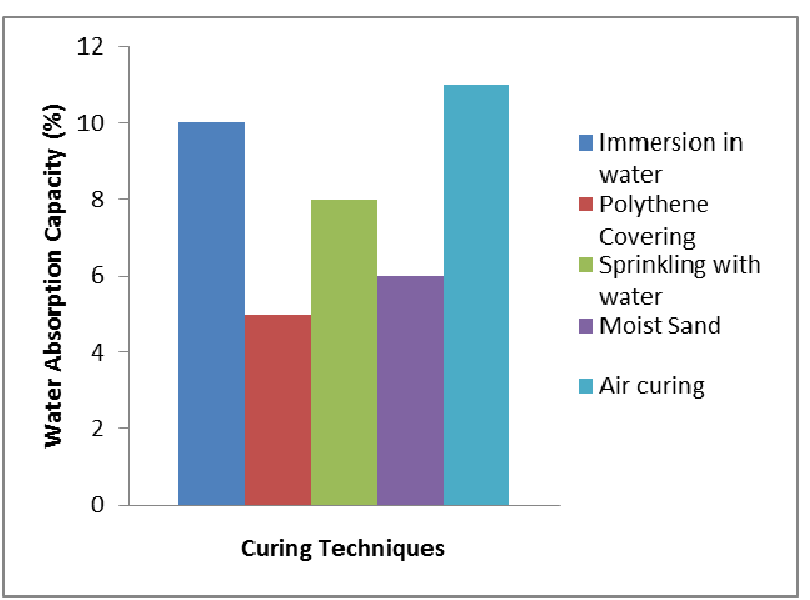

Fig. 6. Water absorption capacity of concrete cured using different techniques

It is possible that the hydration of anhydrous cement was not fully completed due to insufficient moisture, which most of which might be evaporated as against polythene concering and other techniques. The guiding rule is that the more a curing technique could retain moisture required for complete hydration within the concrete matrix the more anhydrous cement reacts with water forming cementitious compound. As more water is consumed the calcium silicate hydrate formed tends to increase volume and hence filling the internal voids. This makes the concrete more compact and resist permeability of water to some extent. These results further confirmed that air curing technique shoud be avoided in practice, especially where strength matter most. On the contrary, polythene covering appeared to perform excellently.

\section{Conclusions}

Effect of curing methods on compressive strength was studied experimentally and regression models were established for each of the methods. The following conclusions were drawn from the study:

i. Curing of concrete is essential in attaining the desired strength of concrete.

ii. Variations in compressive strengths were influenced by the curing techniques depending on their ability to prevent moisture movement from the concrete.

iii. Polythene covering was found to be the most efficient method of curing as compared to the other methods employed.

iv. Regression models established could be used to predict compressive strengths of concrete for different curing techniques considered.

\section{References}

1. CIRIA. Project Report 49, On-site curing - Influence on the durability of concrete: A review (1997)

2. B.L. Gupta, A. Gupta, Concrete Technology. A.K. John Publishers for Standard Publishers Distributors, Nai Sarak, Delhi, India (2004)

3. M. Wanielista, M. Chopra, Compressive Strength of Previous Concrete Pavements. Final Report. FDOT project BD521-02 University of Central Florida. Orlando Florida (2007)

4. G.S. Wojcik, D.R. Fitzjarrald, Journal of Applied Meteorology, 40 (2001)

5. J.B. Chougale, M. Bhagat, S.M. Nagargoje, International Journal of Advance Foundation And Research In Science \& Engineering, 1(2015)

6. M.F. Zain, Y. Matsufuji, Proceedings of the Fifth International Conference on Concrete Engineering and Technology, Kuala Lumpur, Malaysia, (1997)

7. CIP. Concrete in Practice, National Ready Mixed Concrete Association (2000)

8. R. Preetha, S.R. Kishore, C. Sundaramurthy, P.C. Sivathanu, A.K. Laharia, Concrete research letters, 5 (2014)

9. T. James, A. Malachi, E.W. Gadzama, V. Anametemoka, Nigerian Journal of Technology 30 (2011)

10. N.R. Kholia, A.V. Binita, T.G. Tank, International Journal of Advanced Engineering Technology, 4 (2013)

11. A.A. Raheem, A.A. Soyingbe, A.J. Emenike, International Journal of Applied Science and Technology. 3(2013)

12. S.N. Safuddin, Raman, M.F. Zain, Australian Journal of Basic and Applied Sciences, 1 (2007) 
13. Y. B. Raghavendra, M.U. Aswath, International Journal of Advance Scientific Research and Technology, 3 (2012)

14. T.S. Nagesh, "Assessment of the Properties of the Self-Cured concrete", Civil Engineering Portal, http://www.engineeringcivil.com/assessment-of the properties- of-self-cured-concrete.html. (2012). Accesed: 18th September, 2015.

15. S.H. Kosmatka, B. Kerkhoff, W.C. Panarese, "Design and Control of Concrete Mixtures", Fourteenth Edition, Portland Cement Association, USA (2003)

16. BS 1881 - Parts $108 \&$ 116. "Method for making test cubes from fresh concrete \& Method for determination of compressive strength of concrete", British Standard Institution (BSI), London, (1983 )

17. J.G. Cabrera, N. Gowripalan, P.J. Wainwright, Magazine of Concrete Research, 1989, Vol. 41, No. 149, pp.193-198. 1989.
18. BS EN 196-2, Methods of testing cement - Part 2: Chemical analysis of cement', British Standards Institution (BSI), London (1995)

19. BS 1377. "Method of test for soil for civil engineering". British Standard Institution (BSI), London, (1990)

20. D. Ye, D. Zollinger, S. Choi, and M. Won, Literature Review of Curing in Portland Cement Concrete Pavement $2^{\text {nd }}$ edn. (2006) $1-80$.

21. M.A. Rashid, A. Rahman, S. Chakma, M. Rahman, Duet Journal 21 - 15 (2014)

22. Neville A. M. Properties of Concrete, Fourth and Final Edition. John Wiley and Sons, Inc., New York, USA (1996)

23. ACI Committee 318. Building Code Requirements for Structural Concrete and Commentary, 2014

\footnotetext{
Corresponding author: olonade1431ah@gmail.com
} 